\title{
Uso do solo no alto curso do rio Lontra, Tocantins
}

\author{
Cynthia Karyne Tavares Maciel ${ }^{\mathrm{a}}$, Olavo da Costa Leite ${ }^{\mathrm{b} *}$, Daniel Santana Colares ${ }^{\mathrm{c}}$, \\ Allan Deyvid Pereira da Silva ${ }^{\mathrm{d}}$, Jader Nunes Cachoeira ${ }^{\mathrm{b}}$, Maria de Paula Soares da Silva ${ }^{\mathrm{c}}$
}

\footnotetext{
${ }^{\text {a }}$ Instituto Natureza do Tocantins (NATURATINS), Brasil

${ }^{\mathrm{b}}$ Universidade Federal do Tocantins (UFT), Brasil

${ }^{\mathrm{c}}$ Instituto Federal do Tocantins (IFTO), Brasil

${ }^{\text {d } U n i v e r s i d a d e ~ F e d e r a l ~ d o ~ P a r a n a ́ ~(U F P R), ~ B r a s i l ~}$

*Autor correspondente (olavol@ hotmail.com)
}

\section{N F O}

\section{Keywords}

mapping

water course

plant cover

GIS

\begin{abstract}
A B S T R A C T
Usage of soil in the upper course of the Lontra river in Tocantins

Water resources monitoring is a discussing in integration projects and data analysis by different ways, identifying different land uses and occupations. In this sense, geoprocessing techniques gained highlight as a tool for land use and occupation analysis, enhancing activities planning developed in watersheds, considering suitability of available resources and adaptations through agri-environmental management. The objective of this study was to delimit and quantify drainage area of upper course belonging to Lontra river watershed, located in Araguaína-TO, Brazil, considering the limits by the Brazilian Forest Code, and sampling different uses and occupations of land and drainage area conditions and permanent preservation areas (APP). The maps was made by images from Landsat 8 satellite, OLI sensor, 764 band RGB composition and Google Earth images using geoprocessing tools, handled on GIS ArcGIS 10.0 and SIRGAS2000 datum platforms. 23 points were found with alteration in native vegetation cover inside APPs and water source, causing environmental problems, such as erosion processes, siltation, consequently decreasing water volume inside watershed.
\end{abstract}

\section{R E S U M O}

O monitoramento dos recursos naturais tem sido discutido em projetos de integração e análise de dados de natureza diversa, sendo identificados diferentes usos e ocupações do solo. Neste sentido as técnicas de geoprocessamento têm ganhado destaque como ferramenta de análise do uso e ocupação do solo, potencializando o planejamento das atividades a serem desenvolvidas em bacias hidrográficas, considerando a aptidão dos recursos disponíveis e as adequações por meio de gerenciamento agroambiental. $\mathrm{O}$ objetivo deste trabalho foi avaliar as características da rede de drenagem do alto curso do Rio Lontra, município de Araguaína (TO), mostrando os seus diferentes usos e ocupações do solo. Para o desenvolvimento dos mapas, foram utilizadas cartas imagens de satélite Landsat 8, sensor OLI, composição RGB das bandas 764, bem como ferramentas de geoprocessamento, manuseadas em plataformas do SIG e datum SIRGAS2000. Assim, foi constatado que a área de estudo possui uma rede de drenagem característica de cursos perenes, com perfil longitudinal e classificada como de $3^{\mathrm{a}}$ ordem. Além disso, as APP's dos corpos hídricos, até 2015, sofreram uma supressão de vegetação 8,7 ha e a atividade de uso do solo mais predominante na área é a silvicultura de eucalipto. 


\section{INTRODUÇÃO}

O crescimento acelerado da população nas áreas urbanas conduziu-as a uma ocupação desordenada e sem planejamento, acarretando problemas ambientais urbanos como inundações, proliferação de doenças veiculadas a água, deslizamentos de terra, enchentes, aumento do escoamento superficial, dentre outros (Silva, 2016). Distante dos centros urbanos, o uso desordenado do solo das bacias hidrográficas também tem provocado diversos problemas como, desmatamento, incêndios florestais, assoreamentos, fenômenos que estão associados ao manejo inadequado dos solos.

A rede de drenagem é extremamente importante para caracterização e manejo das bacias hidrográficas, determinando suas características de escoamento superficial e o potencial de produção e transporte de sedimento, pois o conhecimento das propriedades hidrológicas é de grande importância para o manejo, especialmente no contexto ambiental, diretamente influenciada pelas características da rede de drenagem (Sousa e De Oliveira, 2017).

$\mathrm{O}$ uso de geotecnologias tem sido amplamente empregado para espacialização de características das bacias hidrográficas. Os Sistemas de Informações Geográficas (SIG's) são um conjunto de Geotecnologias de processamento e manipulação que permitem o levantamento de dados referentes às transformações da dinâmica dos processos morfológicos e morfogenéticos do ambiente, contribuindo para conservação de práticas de manejos em bacias hidrográficas, minimizando os problemas ambientais (Assis et al., 2014).

O estudo sobre a caracterização morfométrica de bacias hidrográficas, pode apresentar resultados integrados com outros parâmetros de cunho hidrológico, como o uso e cobertura da terra, geologia e potencial erosivo que são determinantes como instrumentos de planejamento ambiental (Soares et al., 2016).

Cavalcanti e Marques (2016), em seus estudos ligados aos conflitos em bacias, têm buscado o desenvolvimento moderno de sistema de gestão integrada na bacia hidrográfica em parceria com Agência Nacional de Águas (ANA), com intuito de minimizar as disputas relacionadas aos usos e à distribuição dos recursos hídricos frente a situações de risco de escassez, servindo de base como instrumento efetivo para a resolução de conflitos.

De acordo com Schussel e Nascimento Neto (2015) o estudo de bacias hidrográficas através do diagnóstico dos recursos hídricos, por meio do uso de sensoriamento remoto, possibilita aos gestores públicos atualizarem o diagnóstico de acordo com a periodicidade necessária para análise ambiental.

Para Andrade, Ribeiro e Lima (2016) o uso de modelagem espacial dos dados de sensoriamento remoto facilita o gerenciamento da dinâmica de uso e cobertura de solo em bacia hidrográfica, utilizando modelos matemáticos para modelar a paisagem, sobretudo dados de alterações anuais das áreas de vegetação e uso. Conforme Aparecido et al. (2018) é necessário a obtenção de dados mais concisos sobre o uso e ocupação do solo, em razão da grande relevância destas informações para a análise das características das bacias hidrográficas, colaborando para a melhor gestão e sustentabilidade dos recursos hídricos.

Desta forma, o presente trabalho tem como objetivo avaliar as características da rede de drenagem do alto curso do Rio Lontra, município de Araguaína (TO), mostrando os seus diferentes usos e ocupações do solo.

\section{MATERIAL E MÉTODOS}

\section{Localização da área de estudo}

A área de estudo está situada, políticoadministrativamente, ao norte do estado do Tocantins (Figura 1), totalmente inserida no município de Araguaína. Na bacia hidrográfica, a área estudada está situada no alto curso do Rio Lontra.

\section{Método empregado}

Para a elaboração dos mapas da rede hierárquica, indicação de área com alteração da vegetação nativa em APP's dos corpos hídricos, áreas desmatadas e inserção de silvicultura, foram utilizadas imagens do satélite Landsat 8, sensor OLI, composição RGB das bandas 764, datum SIRGAS 2000 , processado ambiente SIG. As áreas foram mensuradas na projeção cônica de Albers. Foi utilizada a base de dados vetoriais da Secretaria do Planejamento e da Modernização da Gestão Pública do Estado do Tocantins (SEPLAN-TO).

Foi delimitada a área de drenagem e realizados recortes (clip's) a partir de imagens de satélite e arquivos shapefile, através de um banco de dados vetorizados, para obtenção dos mapas cartográficos. Para o dimensionamento da largura da faixa de proteção ambiental do curso hídrico foram considereados os pressupostos legais para APP's, sendo 30 metros de preservação para rios de largura inferior a 10 metros e 50 metros de raio para preservação de nascentes, como preconiza o Código Florestal Brasileiro vigente (BRASIL, 2012). 


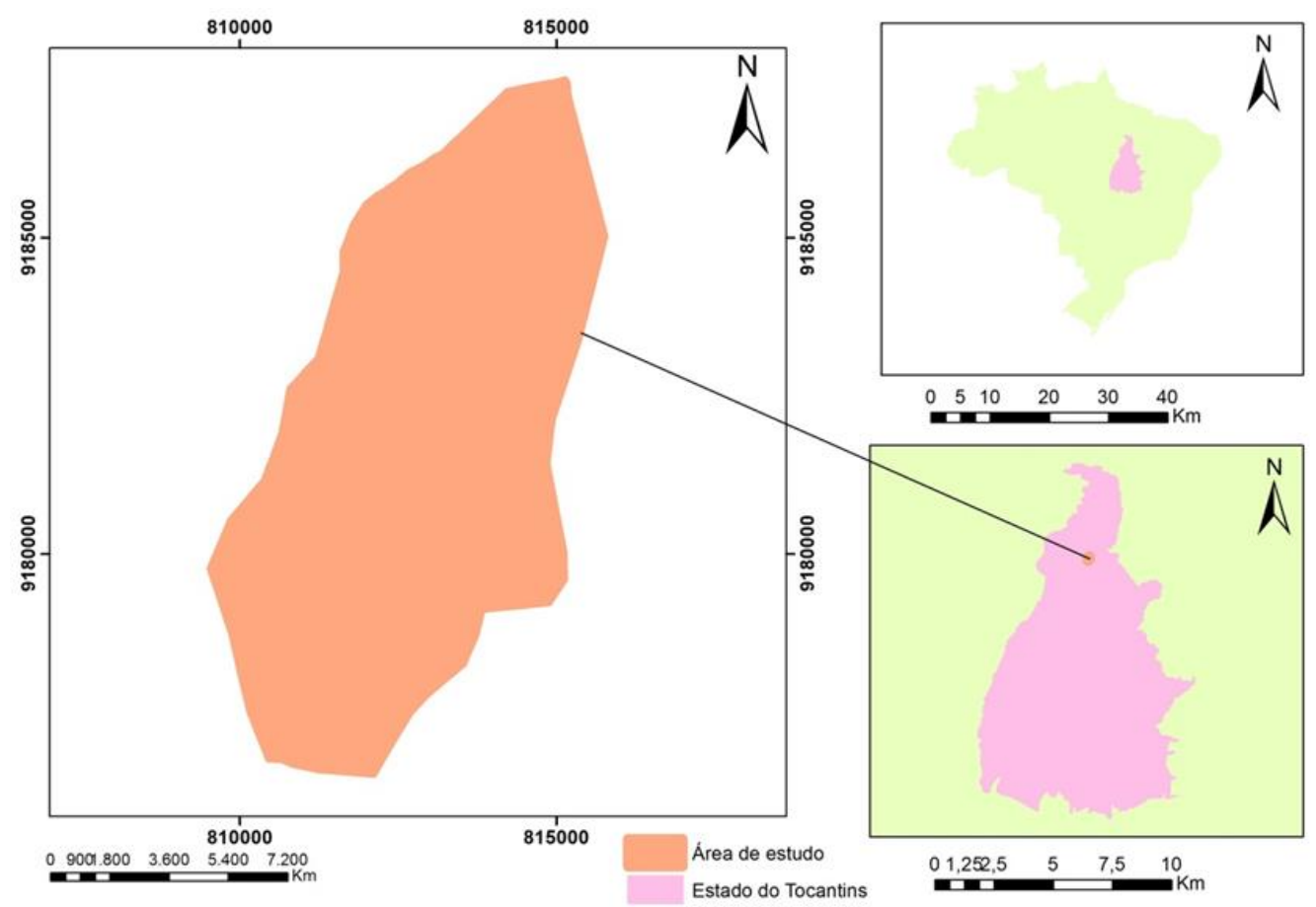

Figura 1 - Localização da área de estudo no estado do Tocantins.

\section{RESULTADOS E DISCUSSÃO}

A partir da delimitação da área do alto curso do Rio Lontra (Figura 1) constatou-se que a sua abrangência é 4.091 hectares, com $12 \mathrm{~km}$ de extensão da nascente principal até o exutório. A delimitação da bacia deve ser compreendida como um dos primeiros procedimentos executados em análises de caracterização de unidade de planejamento, pois favorece o diagnóstico integrado das condições ambientais e sociais (Cardoso et al., 2006).
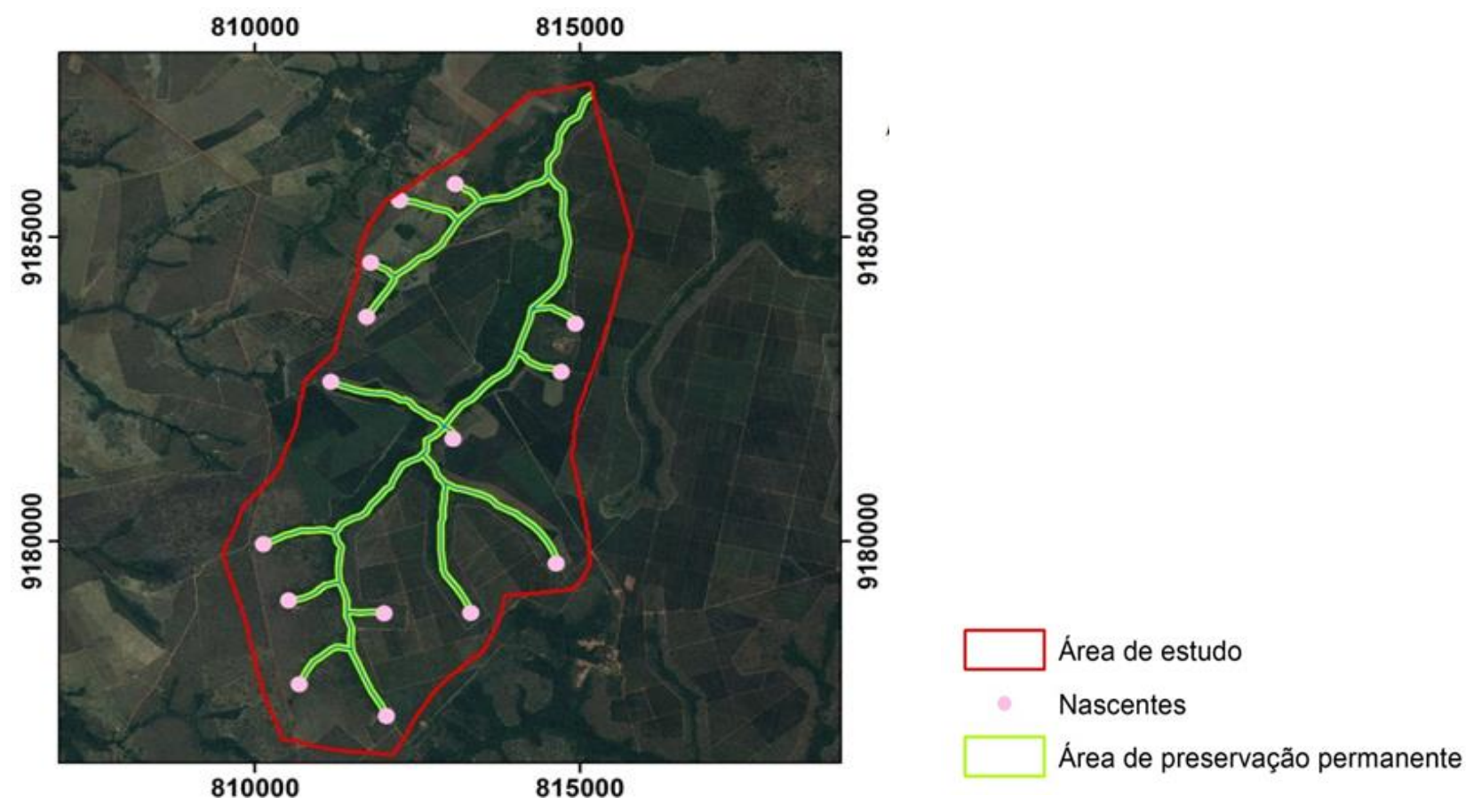

Figura 2 - Localização da área de estudo com carta de imagem da área analisada do alto curso do rio Lontra. 
A morfologia fluvial foi analisada da nascente até a confluência com o córrego Cuia, nas coordenadas UTM fuso 22S E: 815.164 e N: 9.187.457. As figuras 2 e 3 representam o curso d'água da rede de drenagem em análise, sendo de característica de curso perene, determinado pela favorabilidade hidrogeógica do ambiente mantido pelo len- çol freático da área.

A rede hierárquica é apresentada na figura 3 , onde é possível observar que a sua rede hierárquica é composta por dez tributários, sendo oito de $1^{\circ}$ ordem e dois de $2^{\circ}$ ordem, desta forma, verifica-se que o rio Lontra tem perfil longitudinal e é considerado de $3^{\circ}$ ordem.

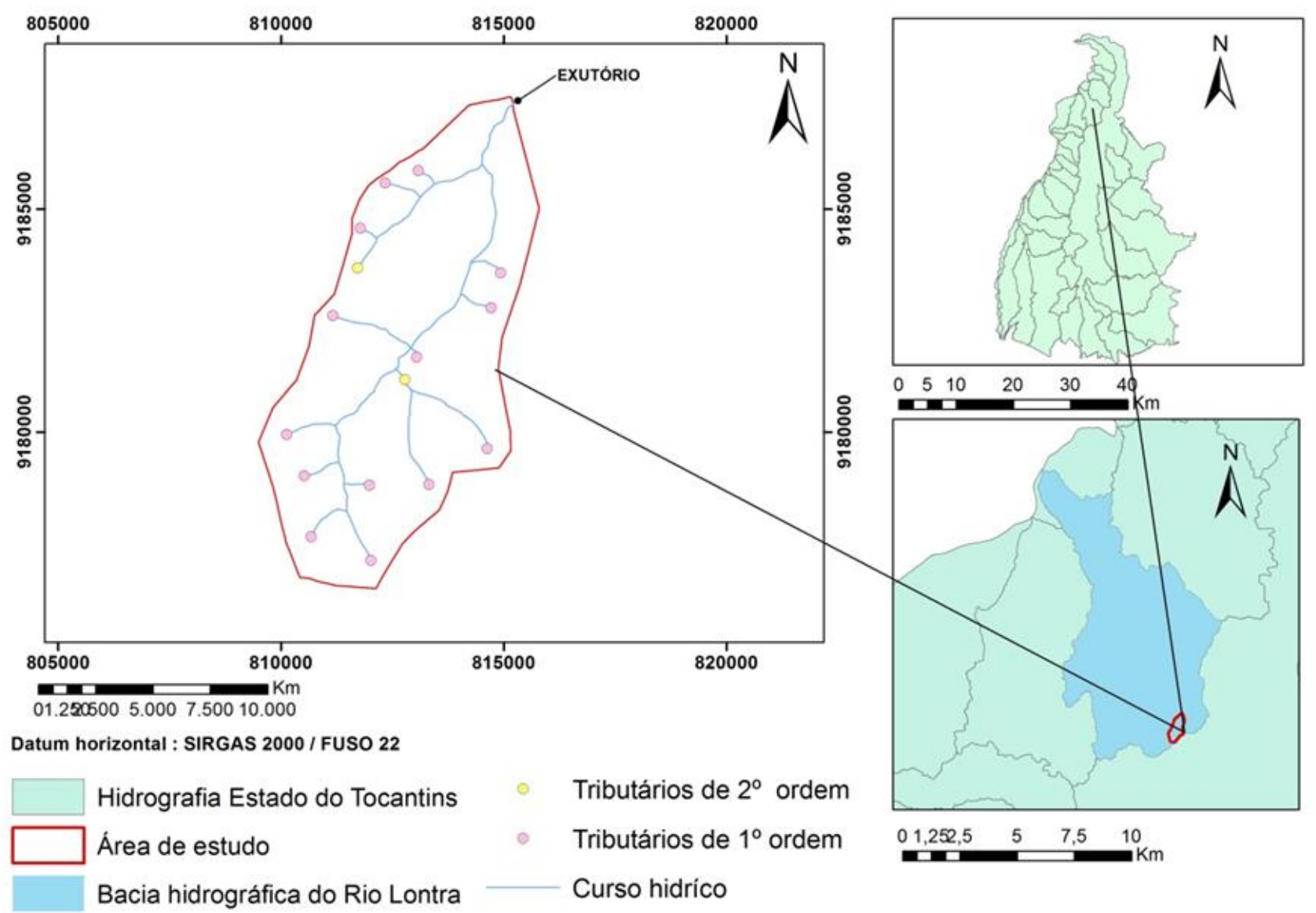

Figura 3 - Mapa temático da rede hierárquica das áreas analisadas do alto curso do rio Lontra.

O trecho alvo do estudo, da nascente ao exutório, possui $12 \mathrm{~km}$ de extensão e perfil transversal, cujo leito varia em determinados pontos entre 2 a 4 metros de largura padrão e apresenta traçado do conjunto dos seus talvegues em padrão de drenagem dendrítico. Esse tipo de padrão assemelha-se a distribuição dos tributários aos galhos de uma árvore.

De acordo com Tonello et al. (2006) as redes de drenagem de até $4^{\mathrm{a}}$ ordem configura-se como pequenas bacias, considera-se que, quanto mais ramificada for a rede, mais eficiente será o sistema de drenagem. Por sua vez, Teodoro et al. (2017) afirmam que as sub-bacias são áreas de drenagem dos tributários do curso d'água principal, frágeis e frequentemente ameaçadas por perturbações, nas quais a escala espacial, temporal e observacional, são fundamentais.

Para tanto, a dimensão da rede de drenagem está diretamente relacionada com a rede hierárquica e declividade do terreno, e a capacidade de transporte contribui para a erosão do canal fluvial. Portanto, o uso e ocupação desordenados com canais acima da primeira ordem são susceptíveis a processos de assoreamento, inundações, alagamento em áreas de topografia mais rebaixadas, as quais devem ser priorizadas em ações de planejamento integradas de gerenciamento dos recursos naturais.

De acordo com Chiaranda et al. (2016) o comportamento hidrológico de uma bacia hidrográfica é função de suas características morfológicas referentes aos aspectos climáticos, físicos, hidrográfi- 
cos, geológicos, geomorfológicos, altimétricos, edáficos e a cobertura vegetal original da área.

A espacialização das áreas de APP e nascentes evidenciou que houve supressão de vegetação em espaços protegidos pelo código florestal (Brasil,
2012). Ao todo foram contabilizados 23 pontos com alteração da cobertura vegetal nativa no interior das APP's de córregos e nascentes, áreas que somadas ocupam 8,75 hectares (Figura 4).

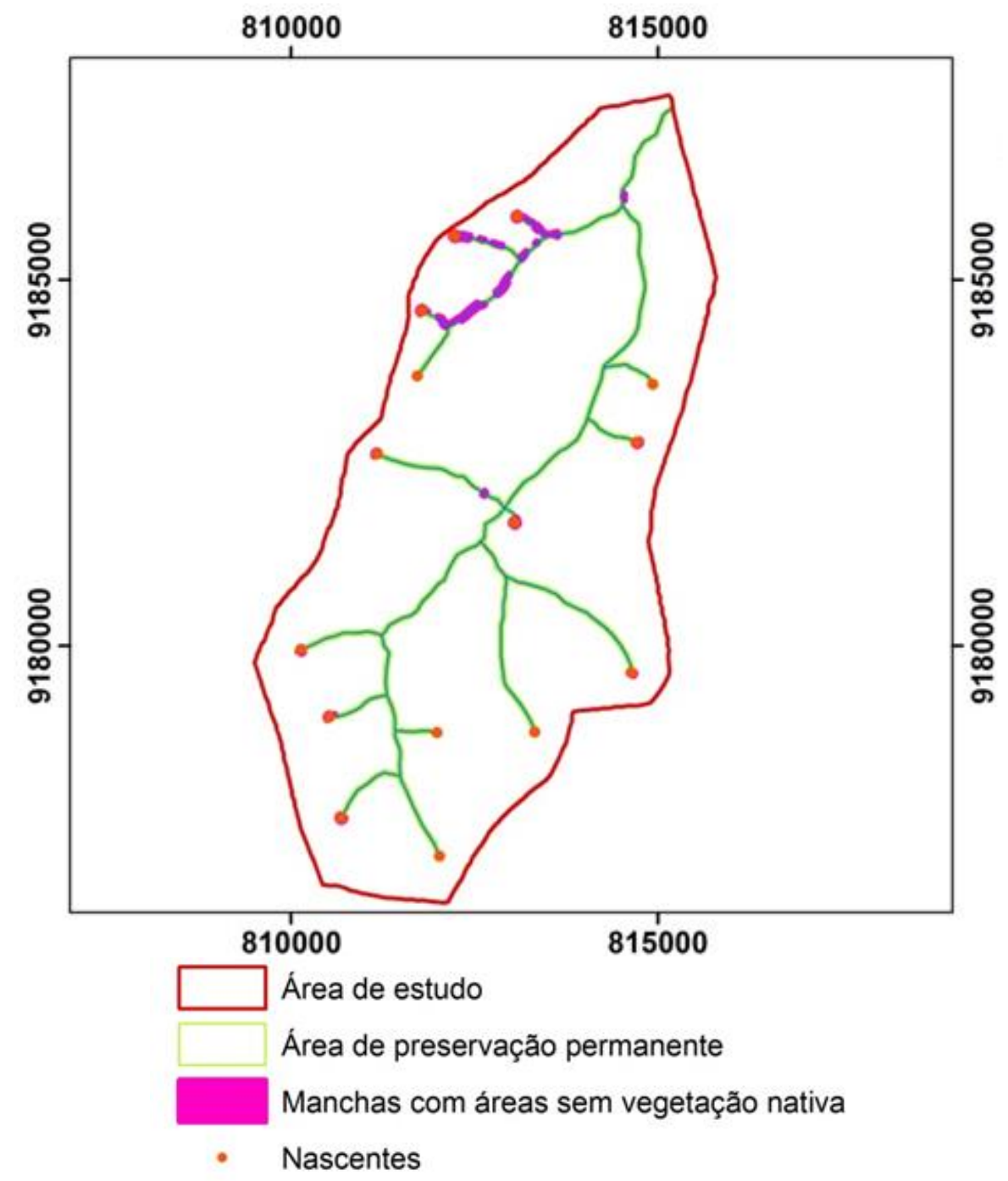

Figura 4 - Mapa da com indicação de área com alteração da vegetação nativa em APP.

As APP's contornam 15 nascentes com raio de proteção de 50 metros. Desta forma, o Código Florestal Brasileiro (Brasil, 2012), determina a preservação da vegetação nativa às margens dos rios e ao redor das nascentes e reservatórios.

Para Alves et al. (2015) o emprego de ferramentas de monitoramento corrobora para o diagnóstico da análise temporal e para uma desaceleração das transformações antrópicas, pois contribui para a fiscalização ambiental mais eficiente. Valle Júnior et al. (2011) destacam que as APP's devem ser protegidas às margens dos rios, lagos, represas, córregos e outros corpos d'água em faixas de largura de acordo a legislação do Código
Florestal Brasileiro.

A partir da espacialização da cobertura do solo nas APP's e cursos d'água verificou-se que algumas áreas ocorrem em zona de contato com áreas ocupadas pela silvicultura e pastagem (Figura 5). Apesar da área não apresentar grande alteração na cobertura vegetal nativa no interior das APP's, há presença de pastagens destinadas à pecuária. Estes resultados reforçam a necessidade de recuperação da cobertura vegetal nativa, reduzindo as perdas de solos, ocasionando aumento da infiltração de água, retenção de sedimentos, conservação do solo e posterior recarga do lençol freático. 

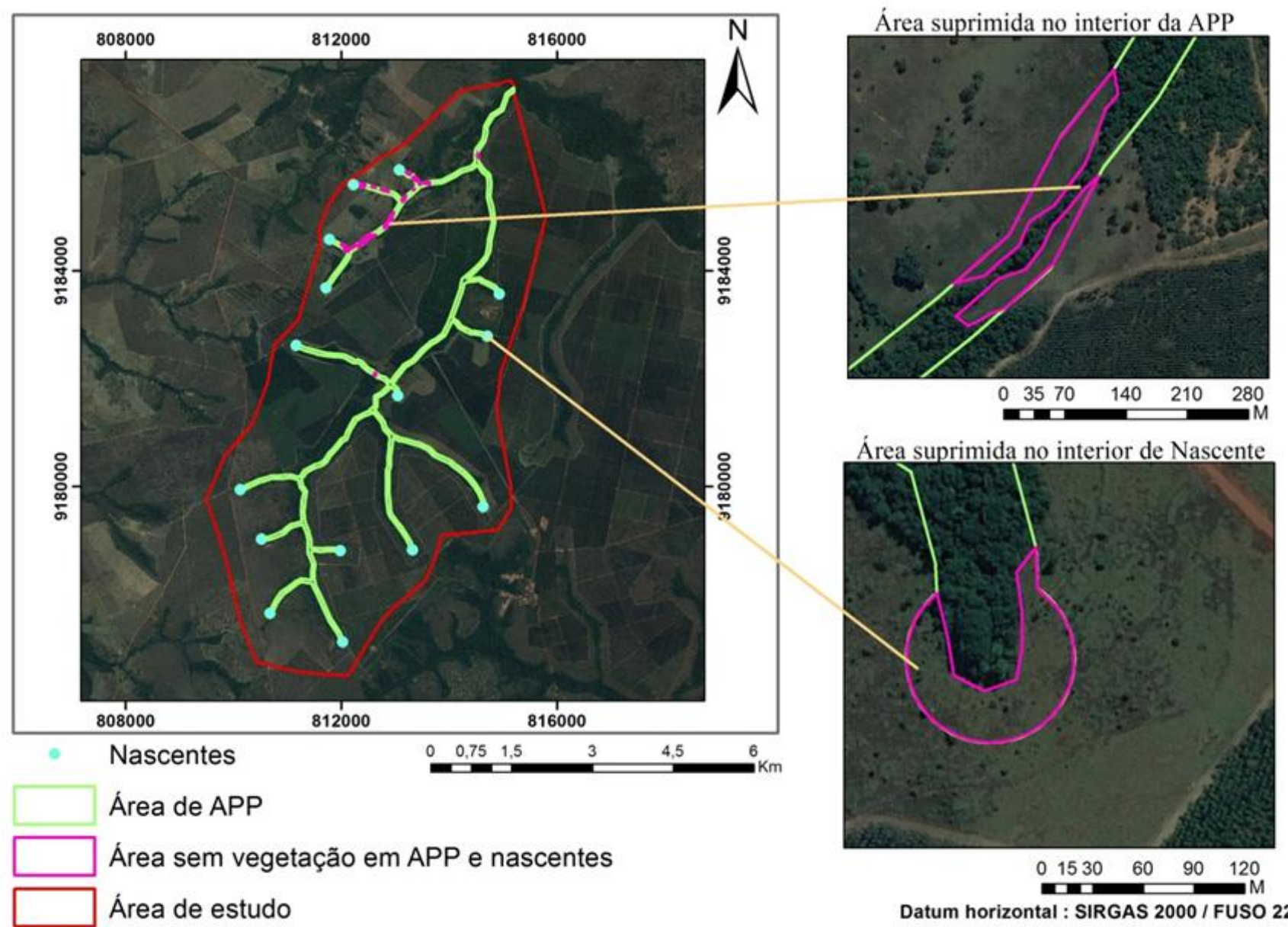

Datum horizontal : SIRGAS 2000 / FUSO 22

Figura 5 - Carta imagem com indicação de supressão em APP de curso d'água e APP de nascente.

O conhecimento sistêmico da área analisada pode servir de instrumento de gerenciamento integrado dos recursos hídricos da bacia por meio do Comitê de Bacia Hidrográfica dos Afluentes da bacia do rio Lontra, alcançando condições necessárias em relação ao estudo científico e tecnológico de caráter multidisciplinar da área.

Almeida et al. (2017) descrevem que a bacia hidrográfica do rio Lontra possui área de agropecuária de 209.006,44 ha para um rebanho de 271.966 animais, aproximadamente 1,30 animal/há. Essa situação deve ser monitorada com maior atenção por parte do órgão gestor dos recursos hídricos, buscando harmonizar a preservação ambiental e a pecuária que é uma importante atividade econômica para o estado do Tocantins.

A figura 6 demonstra a análise espaço temporal do avanço das áreas desmatadas destinadas à silvicultura, não havendo ação de reflorestamento para a recuperação da vegetação nas APPs em nenhuma localidade. Até meados de 2012 a área total ocupada por silvicultura de eucalipto era de 1361 ha, de 2013 até 2015 foram plantados mais 691 ha, um incremento de $27,3 \%$. A área total de silvicultura verificada no ano de 2015 foi 2.523 ha, que corresponde a $51,4 \%$ do auto curso do rio Lontra.

$\mathrm{O}$ efeito da monocultura de eucalipto sobre o solo pode ser positivo ou negativo, dependerá do perfil do ambiente antes da inserção da monocultura. Se o ambiente estava ocupado anteriormente por vegetação nativa, a implantação da floresta plantada seria ambientalmente desfavorável, contudo, se o solo estava ocupado por monocultura de pastagem, então a floresta plantada é ambientalmente positiva (Moledo et al., 2016).

A bacia hidrográfica do rio Lontra, quanto a sua pedologia, é composta por quatro dos grandes grupos de classificações dos solos: Neossolos (197.133 ha, 52,4\%), Argissolos (138.969 ha, 37\%), Latossolos (34.021 ha, 9\%) e Plintossolos (5.992 ha, 1,6\%) (Figura 7). 


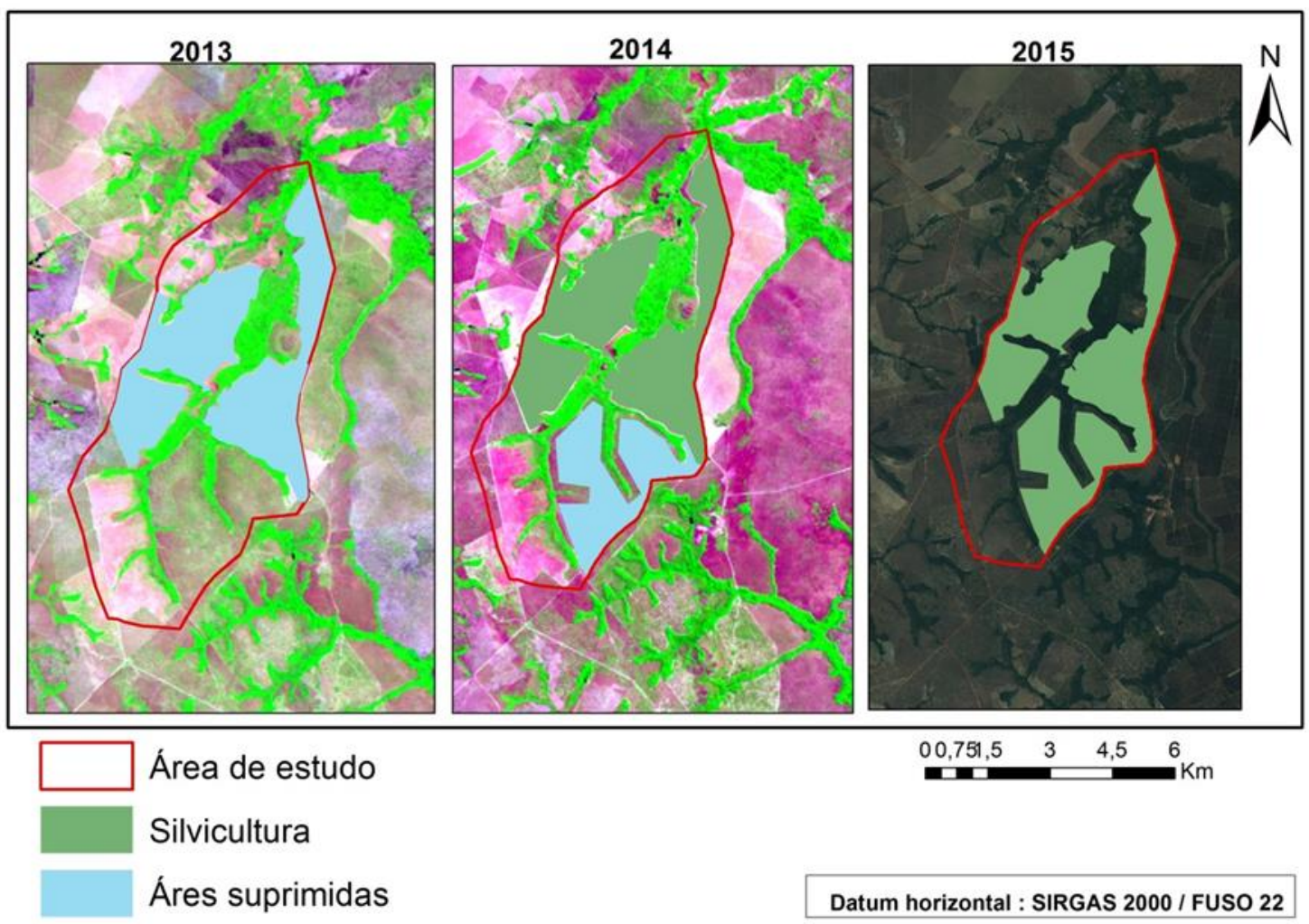

Figura 6 - Carta imagem com análise espaço temporal do avanço de áreas desmatadas e inserção da silvicultura.

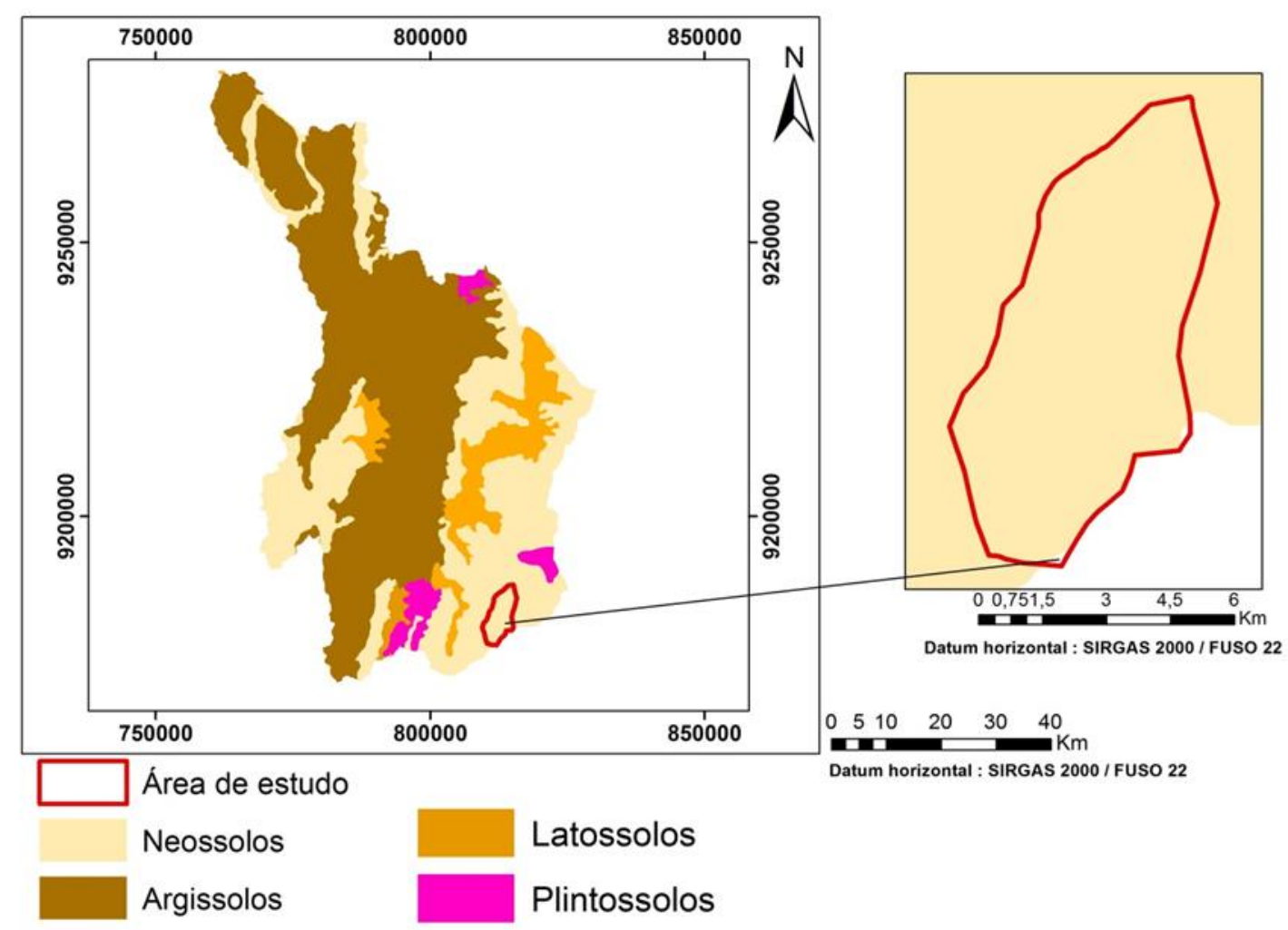

Figura 7 - Mapa de distribuição dos solos da bacia do rio Lontra e da área de estudo. 
A partir mapeamento pedológico da bacia do rio Lontra verificou-se que seu alto curso, delimitado neste trabalho como área de estudo, possui apenas uma tipologia de solo, o Neossolo (Figura 7). De acordo com Oliveira e Francisco (2018), os dados espectrais, podem ser utilizados como instrumento no mapeamento, no uso técnico de sensoriamento remoto, na identificação de panoramas agrícolas regionais e, sobretudo nacionais, para que isso seja possível, é preciso que mapas sejam feitos e em escala compatível para análise ou fins de estimativas de áreas agrícolas. Dessa forma, na área de estudo é necessário buscar outros métodos que favoreçam o melhor detalhamento sobre dos tipos e classes de solos na área do alto curso do rio Lontra.

Através da quantificação de uso e cobertura do solo realizada, verificou-se que a atividade de uso que ocupa maior área é a silvicultura com 2.523 ha (51,4\%), sendo o Eucalyptus é a espécie florestal exótica cultivada; as pastagens ocupam 407,07 ha $(8,3 \%)$; as formações de Floresta Ombrófila ocupam 800,18 ha $(23,4 \%)$; o Cerrado Sentido Restrito ocupa 668,16 ha $(13,6 \%)$; e a formação do tipo capoeira ocupa 163,6 ha $(3,3 \%)$. Leite et al. (2019) apontam que a fitofisionomia natural da área da bacia Muricizal que faz divisão com a bacia Lontra apresentam formações de vegetal de Cerrado e Amazônica, como: Floresta Ombrófila Aberta, Floresta Ombrófila/Floresta Estacional Decidual e Savana / Floresta Estacional Semidecidual. Na figura 8 é possível verificar a espacialização destas informações de uso e cobertura do solo.

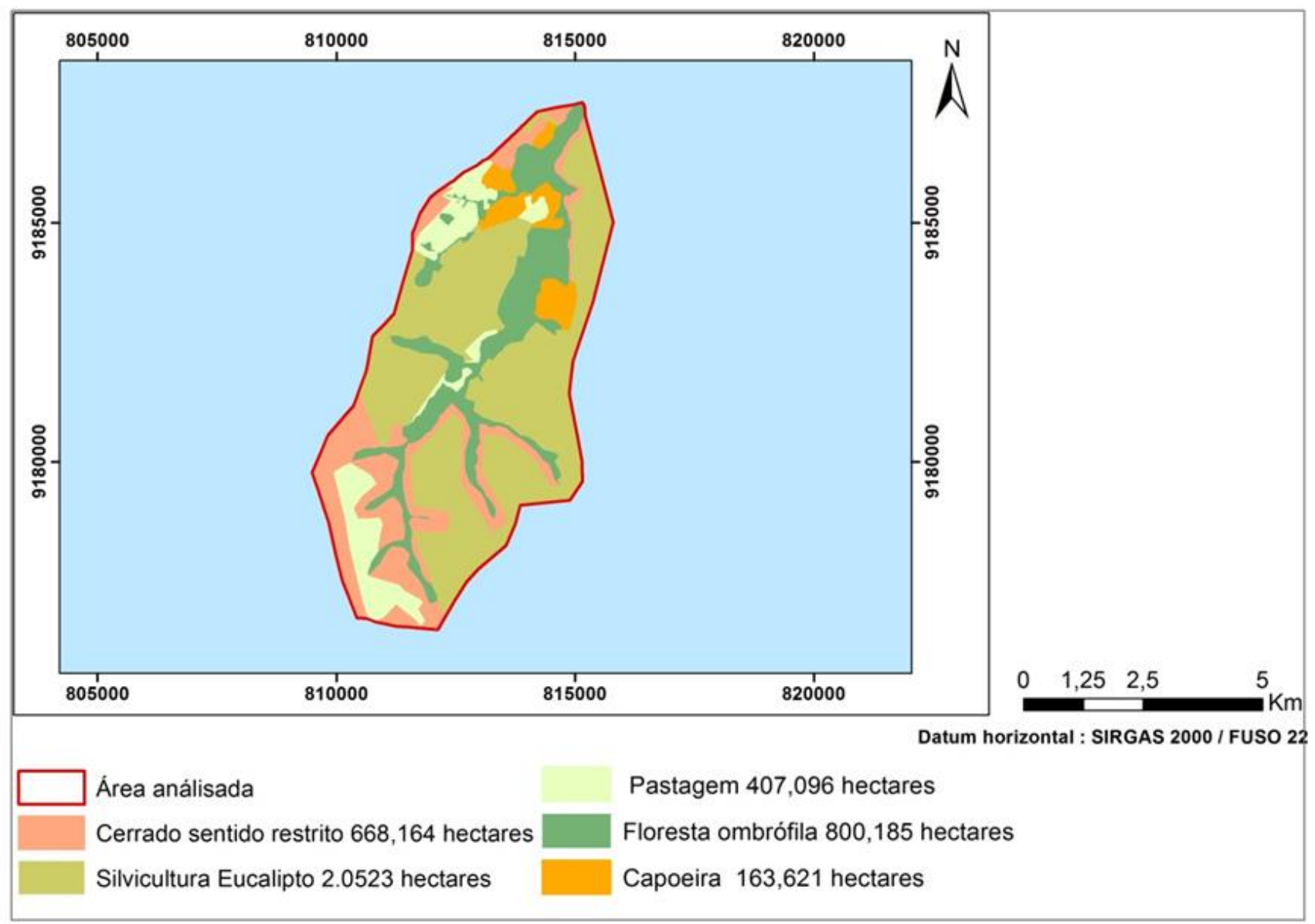

Figura 8 - Mapa de uso e ocupação do solo da área de drenagem analisada.

As tecnologias que possibilitam a espacialização dos recursos naturais por meio de imageamento são fundamentais para a subsidiar um desenvolvimento sustentável das atividades econômicas rurais. As variações dos atributos físico-hídricos e químicos permite estabelecimento de avaliação do seu potencial agrícola, além da elaboração de zoneamentos mais adequados ao planejamento de uso e a gestão sustentável dos recursos naturais, como solo, água e biodiversidade (Donagemma, 
2016). Desta forma a utilização de imagens orbitais espacial na obtenção estudos em bacias hidrográficas, fornece subsídios para mapeamento de uso e ocupação do solo, auxiliando no planejamento para o uso e exploração dos recursos naturais (Vaeza, Maia e Disperati, 2010).

\section{CONCLUSÕES}

A partir desta pesquisa foi possível concluir que a área de estudo, região do auto curso do rio Lontra, apresenta uma rede de drenagem característica de cursos perenes, com perfil longitudinal e classificada como de $3^{a}$ ordem. A área é ocupada totalmente por Neossolo. As áreas de preservação permanente dos corpos hídricos possuem, pelo menos, 8,75 ha de áreas naturais que foram suprimidas e carecem reflorestamento. E com base no uso do solo as pressões por espaço estão sendo exercidas, principalmente, pela silvicultura de eucalipto que ocupava até 2015 mais de $51 \%$ do território da área analisada.

\section{AGRADECIMENTOS}

Os autores agradecem a Coordenação de Aperfeiçoamento de Pessoal de Nível Superior - CAPES, a Universidade Feral do Tocantins - UFT e a Universidade Federal do Paraná - UFPR.

\section{REFERÊNCIAS BIBLIOGRÁFICAS}

ALMEIDA, L.N.; FIGUEROA, F.E.V.; MACIEL, G.F.; DE OLIVEIRA, R.M. Impacto da demanda para dessedentação do rebanho bovino na disponibilidade hídrica: o caso da bacia do Rio Lontra. Engenharia Ambiental: Pesquisa e Tecnologia, Espírito Santo do Pinhal, v.14, n.1, p.86-97, 2017.

ALVES, F.; DE LIMA, K.C.C.; VIOLA, M.R.; DE SOUZA, P. A.; GIONGO, M.; DE MELLO, C.R. Avaliação temporal dos conflitos de uso do solo na bacia hidrográfica do rio Formoso, Tocantins. Pesquisa Florestal Brasileira, Brasília, v.35, n.83, p.271-283, 2015.

ANDRADE, M.P.; RIBEIRO, C.B.M; LIMA, R.N.L. Modelagem dinâmica da mudança do uso e cobertura do solo na bacia hidrográfica do rio Paraíba do Sul a partir de imagens MODIS e um modelo de sub-regiões. Revista brasileira de cartografia, Monte Carmelo, v.68, n.5, p.965-978, 2016.

APARECIDO, C.F.F.; VANZELA, L.S.; VAZQUEZ, G.H.; LIMA, R.C. Manejo de bacias hidrográficas e sua influência sobre os recursos hídricos. Irriga, Botucatu, v.21, n.2, p.239-256, 2018.

ASSIS, J.M.O.; CALADO, L.O.; SOUZA, W.M.; SOBRAL, M.C. Mapeamento do uso e ocupação do solo no município de Belém de São Francisco - PE nos anos de 1985 e 2010. Revista Brasileira de Geografia Física, Recife, v.7, n.5, p.859-870, 2014. Disponível em: <http://www.revista.ufpe.br/rbgfe/index.php/revista/article/ viewFile/1056/615>. Acesso em: 25 mar. 2019.
BRASIL. Lei $\mathrm{n}^{\circ} 12.651$, de 25 de maio de 2012. Institui o Novo Código Florestal Brasileiro. Diário Oficial [da] República Federativa do Brasil, Brasília, DF, v. 149, n. 102, p. 1-10, 25 maio 2012. Disponível em: <http://www.planalto.gov.br/ccivil_03/_Ato20112014/2012/Lei/L12651.htm>. Acesso em: 15 jul 2019.

CARDOSO, C.A.; DIAS, H.C.T.; SOARES, C.P.B.; MARTINS, S.V. Morphometric characterization of Debossan river watershed, Nova Friburgo, RJ. Revista Árvore, Viçosa, v.30, n.2, p.241-248, 2006.

CAVALCANTI, B.S.; MARQUES, G.R.G. Recursos hídricos e gestão de conflitos: A bacia hidrográfica do rio Paraíba do Sul a partir da crise hídrica de 2014-2015. Revista de Gestão dos Países de Língua Portuguesa, Rio de Janeiro, v.15, n.1, p.4-16, 2016.

CHIARANDA, R.; RIZZI, N.E.; COLPINI, C.; SOARES, T. S. Projeção do uso da terra e do potencial de armazenamento da Bacia Hidrográfica do Rio Cuiabá. Geoambiente On-line, Jataí, n.26, p.19-32, 2016.

DONAGEMMA, G.K.; FREITAS, P.L.D.; BALIEIRO, F.D.C.; FONTANA, A.; SPERA, S.T.; LUMBRERAS, J.F; MACEDO, M.C.M. Characterization, agricultural potential, and perspectives for the management of light soils in Brazil. Pesquisa Agropecuária Brasileira, Brasília, v.51, n.9, p.1003-1020, 2016.

LEITE, O.C.; LIMA, S. O.; OLIVEIRA, L.N.; SILVA, R.J.; FREITAS. G.A.; SILVA, A.D.P.; JUNIOR, O.J.F. Morphometric characterization of part of muricizal river watershed -Tocantins, Brazil. Revista Agri-Environmental Sciences, Palmas-TO, v.5, p.1-15, 2019.

MOLEDO, J.C.; SAAD, A.R.; DALMAS, F.B.; ARRUDA, R.D.O.M.; CASADO, F. Impactos ambientais relativos à silvicultura de eucalipto: uma análise comparativa do desenvolvimento e aplicação no plano de manejo florestal. Geociências, São Paulo, v.35, n.4, p.512-530, 2016.

OLIVEIRA, T.G.; FRANCISCO, C.N. Mapeamento das Áreas de Preservação Permanente e as Mudanças no Código Florestal. Caderno de Geografia, Belo Horizonte, v.28, n.54, p.574-587, 2018.

SCHUSSEL, Z.; NASCIMENTO NETO, P. Urban planning based on watersheds: From theoretical debate to municipal management. Ambiente \& Sociedade, [S.1], v.18, n.3, p.137-152, 2015.

SILVA, R.F. Análise dos impactos ambientais da Urbanização sobre os recursos hídricos na sub-bacia do Córrego Vargem Grande em Montes Claros-MG. Caderno de Geografia, Belo Horizonte, v.26, n.47, p.966-976, 2016.

SOARES, L.S., LOPES; W.G.R., CASTRO; A.C.L.; DE ARAUJO, G.M.C. Análise morfométrica e priorização de bacias hidrográficas como instrumento de planejamento ambiental integrado. Revista do Departamento de Geografia, São Paulo, v.31, p.82-100, 2016.

SOUSA, M.M; DE OLIVEIRA, W. Análise morfológica da rede de drenagem do alto Juruá/AC, extraída de MDESRTM. Caminhos de Geografia, Uberlândia, v.18, n.61, p.44-64, 2017.

TEODORO, V.L.I.; TEIXEIRA, D.; COSTA, D.J.L.; FULLER, B.B. O conceito de bacia hidrográfica e a importância da caracterização morfométrica para o entendimento da 
dinâmica ambiental local. Revista Brasileira Multidisciplinar, Araraquara, v.11, n.1, p.137-156, 2007.

TONELLO, K.C.; DIAS, H.C.T.; SOUZA, A.L.; RIBEIRO,

C.A.A.S.; LEITE, F.P. Morfometria da bacia hidrográfica da Cachoeira das Pombas, Guanhães -MG. Revista Árvore, Viçosa, v.30, n.5, p.859-870, 2006.

VAEZA, R.F.; MAIA, A.G.; DISPERATI, A.A. Uso e ocupação do solo em bacia hidrográfica urbana a partir de imagens orbitais de alta resolução. Floresta e Ambiente, Seropédica, v.17, n.1, p.23-29, 2010.

VALLE JÚNIOR, R.F.; FERREIRA, A.F.; CHAVES, L.H.; ABDALA, V.L. Diagnóstico das áreas de preservação permanente na bacia hidrográfica do rio Tijuco, Prata MG, utilizando tecnologia SIG. Global Science and Technology, Rio Verde, GO, v.4, n.1, p.105-114, 2011. 